\title{
ELECTROPHILIC AND NUCLEOPHILIC CHEMICAL REACTIVITY OF NEUTRAL AND ANIONIC FORMS OF 4-CPA, 24D-CPA, 34-CPA AND 245T-CPA THROUGH CONCEPTUAL DFT REACTIVITY DESCRIPTORS.
}

\author{
L. H. MENDOZA-HUIZAR ${ }^{I, *}$, C.H. RIOS-REYES ${ }^{l}$, G.A. ÁLVAREZ-ROMERO', M.E. PALOMAR-PARDAVÉ', \\ M.T. RAMÍREZ-SILVA
}

${ }^{1}$ Universidad Autónoma del Estado de Hidalgo. Academic Area of Chemistry. Carretera Pachuca-Tulancingo Km. 4.5 Mineral de la Reforma, Hgo, México.
${ }^{2}$ Universidad Autónoma Metropolitana-Azcapotzalco, Departamento de Materiales, C.P. 02200 México, D.F., México.
${ }^{3}$ Universidad Autónoma Metropolitana-Iztapalapa, Departamento de Química, Av. San Rafael Atlixco \#186, Col. Vicentina, C.P. 09340, México, D.F., México

\section{ABSTRACT}

In the present work, we have analyzed the electrophilic and nucleophilic chemical reactivity of the neutral and anionic chlorophenoxyacetic acid herbicides, 4-CPA, 24D-CPA, 34-CPA and 245T-CPA at the X/6-311++G(2d,2p) level of theory (where X=wB97XD, MPW91B1K and MP2). Chemical reactivity was analyzed in the aqueous phase and employing global and local DFT reactivity descriptors. The structural parameters derived from DFT calculations are equivalent to those obtained at the MP2 level. The Fukui Function values suggest that nucleophilic attacks to the neutral and anionic forms would cause dechlorination on 24D-CPA, 34-CPA and 245T-CPA and hydrogen abstraction in 4-CPA. At pH values lower than 2.7, electrophilic attacks would cause the cleavage of the ether bond in 4-CPA, 24D-CPA and 34-CPA and dechlorination in 245T-CPA. But, at pH > 3.6, electrophiles may cleave the ether bond to start the degradation of the four CPAs.

Keywords: 4-CPA; 24D-CPA; 34-CPA; 245T-CPA; reactivity; Fukui.

\section{INTRODUCTION}

Chlorophenoxyacetic acids (CPAs) are widely used as plant growth regulators, herbicides and post-emergence pesticides for a selective control of broadleaf weeds. ${ }^{1,2}$ The structure of these CPAs involves an aliphatic carboxylic acid moiety which is attached to a chlorine substituted aromatic ring by an ether bond, see Figure 1, where the position of the halogen has been associated with their toxicity. ${ }^{3-5}$ It has been reported that CPAs resist biodegradation and have potential toxicity towards humans and animals because they increase the vulnerability of mammals to infectious diseases and cancers. ${ }^{6-10}$ Also, CPAs herbicides may generate waste products and contaminate water continuously. Therefore, there is a great interest in developing efficient degradation methods to remove these herbicides from water and soils. ${ }^{11}$ Most of the techniques used for CPAs degradation are based on the generation of hydroxyl radicals $(\mathrm{OH} \cdot)^{12,13}$ Other methods involve bacterial degradation characterized by an initial ether cleavage followed by oxidative dechlorination of the resulting dichlorophenol and ortho cleavage of the aromatic ring. ${ }^{14-16}$ Also, electrochemical techniques such as anodic oxidation and indirect electroxidation methods based on $\mathrm{H}_{2} \mathrm{O}_{2}$ electrogeneration have been employed to degrade CPAs. ${ }^{17}$ In most of the cases, the accepted degradation mechanism suggests that CPAs may be cleaved to form chlorophenol and, possibly, two-carbon fragments. However, despite their danger as potential water contaminants, the chemical reactivity of these compounds is often not well understood. ${ }^{18-22}$ Therefore, a good knowledge of their reactivity may be an important factor for developing efficient degradation methods. In this sense, the accepted theories of the quantum chemistry provide theoretical methodologies which allow analyzing the reactivity of a system at the molecular level. Some theoretical quantum studies have suggested that the proper orientation of the $\mathrm{COOH}$ group and the phenyl moiety modify the reactivity of these herbicides. ${ }^{3}$ Ren et al carried out a Density Functional Theory (DFT) study in which free radicals $(\mathrm{OH} \bullet)$ attacks one of three positions of 4-Chlorophenoxy acetic Acid (4-CPA), 2,4-dichlorophenoxy acetic acid (24D-CPA), 2-methyl-4-chlorophenoxyacetic acid, 2-(2,4dichlorophenoxy)propanoic acid and 2-(4-chloro2-methylphenoxy) propanoic acid herbicides. ${ }^{23}$ They modeled the $\mathrm{H}$-atom abstraction reactions in the $-\mathrm{CH}_{2}-$ group and found that the $\mathrm{OH} \bullet$ addition on the aromatic ring presents the highest and lowest energy barriers. It is important to mention that only the free radical attacks on these CPAs have been analyzed in the literature by which the electrophilic and nucleophilic chemical reactivity exhibited by these acid herbicides are missing. Under these conditions the proposal of new efficient degradation methods employing electrophiles and nucleophiles is a topic of interest Moreover, if one considers that in an aqueous environment at $\mathrm{pH}>7$ carboxyl groups are usually deprotonated; then the anionic forms of chlorophenoxy acetic acids may be predominant under the $\mathrm{pH}$ conditions of surface waters, ${ }^{24}$ and a change on the chemical reactivity; in comparison to the neutral forms may be expected. To the best of our knowledge, the global and local reactivity descriptors, of 4-CPA, 24D-CPA, 3,4-dichlorophenoxy acetic acid (34-CPA) and 2,4,5-trichlorophenoxy acetic acid (245T-CPA), in their neutral and anionic forms are still missing. Thus, in the present work we have carried out a theoretical DFT study to analyze the electrophilic and nucleophilic reactivity of these CPAs. We consider that this kind of study will contribute to get a better understanding of the nucleophilic and electrophilic reactivity of these herbicides.<smiles>[X]c1cc(OC([2H])C(=O)O)c([X])c([X])c1Cl</smiles>

Figure 1. General structure of chlorophenoxy acetic acids studied in the present work.

\section{Theory}

Within the framework of the DFT, it is possible to define global reactivity parameters which give information about the general behavior of a molecule. ${ }^{25}$ These parameters are the electronic chemical potential $(\mu)$, the electronegativity $(\chi)$, and hardness $(\eta)$, which are defined as: ${ }^{25-31}$

$$
\begin{aligned}
& \mu=\left(\frac{\partial E}{\partial N}\right)_{v(r)}=-\frac{1}{2}(I+A) \\
& \chi=-\mu
\end{aligned}
$$


$\eta=\left(\frac{\partial \mu}{\partial N}\right)_{v(r)}=\left(\frac{\partial^{2} E}{\partial N^{2}}\right)_{v(r)}=(I-A)$

In these equations, $E, N$ and $v(r)$ are the energy, number of electrons and the external potential of the system, respectively, while $I$ and $A$ correspond to the vertical ionization potential and vertical electronic affinity, respectively. Another global reactivity descriptor is the global electrophilicity index $(\omega)$ defined as a measurement of the susceptibility of a chemical specie to accept electrons, which can be calculated as: ${ }^{32}$

$$
\omega=\frac{\mu^{2}}{2 \eta}
$$

Additional to the global reactivity parameters, the local reactivity of a molecular system can be evaluated through the Fukui function $(f(r))$, defined as: ${ }^{34-38}$

$$
f(\vec{r})=\left(\frac{\partial \rho(\vec{r})}{\partial N}\right)_{v(\vec{r})}=\left(\frac{\partial \mu}{\partial v(\vec{r})}\right)_{N}
$$

where $r(r)$ is the electronic density. The Fukui function (FF) can be evaluated by using a finite difference approximation. However, due to the discontinuity of the electron density with respect to $N$, this approximation leads to three types of FF for a system, namely, $f^{+}(r), f(r)$ and $f^{\circ}(r)$ for nucleophilic, electrophilic, and free radical attacks respectively. ${ }^{34}$

$$
\begin{aligned}
& f_{k}^{+}(\vec{r})=\rho_{N+1}^{k}(\vec{r})-\rho_{N}^{k}(\vec{r})_{N}^{k} \\
& f_{k}^{-}(\vec{r})=\rho_{N}^{k}(\vec{r})-\rho_{N-1}^{k}(\vec{r}) \\
& f_{k}^{0}(\vec{r})=\rho_{N+1}^{k}(\vec{r})-\rho_{N-1}^{k}(\vec{r})
\end{aligned}
$$

a)

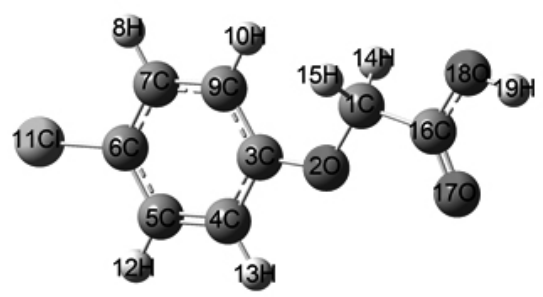

c)

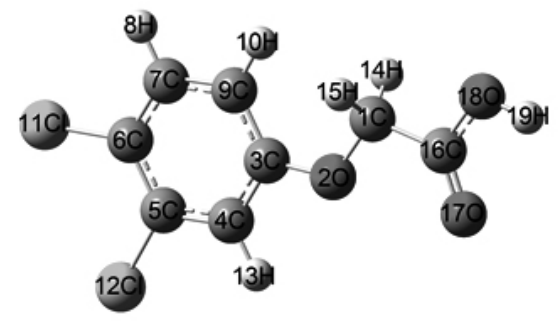

\section{Methodology}

The optimal conformations of the CPAs were subjected to full geometry optimization employing the functionals MPW91B1K, ${ }^{39}$ and wB97XD. ${ }^{40}$ MPW91B1K has been considered as an excellent method to study the electronic properties of chlorinated organic compounds, ${ }^{23}$ while that wB97XD is used to analyze the influence of the dispersive interactions. A triple-zeta quality basis set with polarization and diffuse functions denoted as $6-311 \mathrm{G}++(2 \mathrm{p}, 2 \mathrm{~d})^{41,42}$ was used in conjunction with the PCM solvation model. ${ }^{43,44}$ The optimized geometries at the DFT level were reoptimized employing the PCM solvation model at the MP2/6-311G++(2d,2p) level of theory. ${ }^{45}$ All the calculations here reported were carried out with Gaussian $09,{ }^{46}$ and visualized with GaussView V. $3.09 .{ }^{47}$

\section{RESULTS AND DISCUSSION}

4.1 Global and local reactivity descriptors for neutral CPAs at the DFT level.

Figure 2 shows the optimized structures of 4-CPA, 24D-CPA, 34-CPA and 245T-CPA at the wB97XD/6-311++G(2d,2p) level of theory, in the aqueous phase. The XYZ coordinates of these structures are reported in Table 1S$4 \mathrm{~S}$ as supplementary material. Also, the structures showed in Figure 2 were optimized at the MPW91B1K/6-311++G(2d,2p) level of theory (not shown). It is interesting to note that 4-CPA, 24D-CPA and 34-CPA are exhibiting planar geometries but 245T-CPA result to be non planar. This result suggests a molecular destabilization on 245T-CPA caused by chloride atom in position 2, see Figure 1.

In order to calculate the global reactivity descriptors for the CPAs, we have calculated the value of the vertical affinity energy as $A=E(N)-E(N+1)$ where $E(N)$ and $E(N+1)$ are the total ground-state energies in the neutral $N$ and singly charged $(N+1)$ configurations while the ionization potential was calculated as $I=E(N-1)-E(N)$. The values of $\mu, \eta, \omega$ were calculated employing the equations (1), (3) and (4) and their values are reported in Table 1. At the MPW91B1K/6-311++G(2d,2p) and wB97XD/6$311++\mathrm{G}(2 \mathrm{~d}, 2 \mathrm{p})$ levels of theory, the hardness values are similar, see Table 1 , which indicates that these four CPAs have similar stability. Also, note that the $m$ and $w$ values are very close indicating similar nucleophilic behavior. This result is consistent at the MPW91B1K/6-311++G(2d,2p) and wB97XD/6$311++G(2 d, 2 p)$ levels of theory

b)

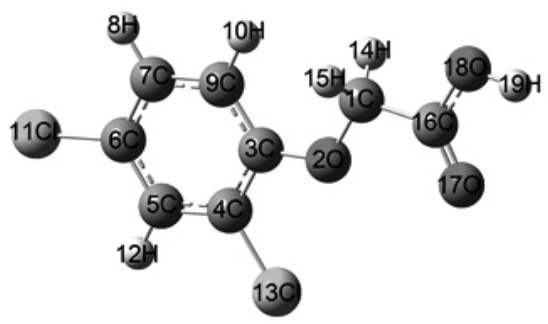

d)

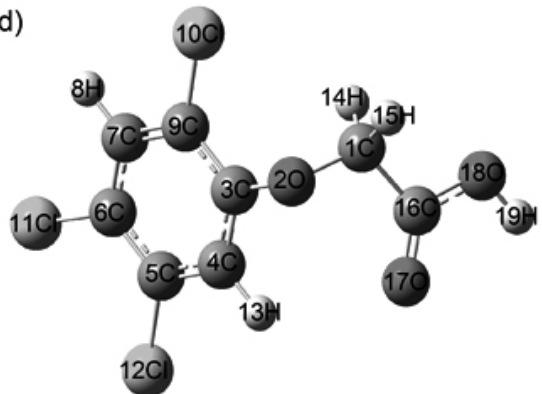

Figure 2. Optimized structures of CPAs at the level wB97XD/6-311++G(2d,2p) level of theory in the aqueous phase, a) 4-CPA, b) 24D-CPA, c) 34-CPA and d)245T-CPA. 
Table 1. Global reactivity descriptors for 4-CPA, 24D-CPA, 34-CPA and 245T-CPA at the MPW91B1K/6-311++G(2d,2p) and wB97XD/6-311++G(2d,2p) levels of theory in the aqueous phase according to equations (1), (3) and (4).

\begin{tabular}{|c|c|c|c|c|c|c|}
\hline & $\eta$ & $\mu$ & $\omega$ & $\eta$ & $\mu$ & $\omega$ \\
\cline { 2 - 7 } & $/ \mathrm{eV}$ & $/ \mathrm{eV}$ & $/ \mathrm{eV}$ & $/ \mathrm{eV}$ & $/ \mathrm{eV}$ & $/ \mathrm{eV}$ \\
\hline & & MPW91B1K & & & wB97XD & \\
\hline 4-CPA & 5.5 & -2.8 & 0.7 & 5.5 & -2.7 & 0.7 \\
\hline $24 \mathrm{D}-\mathrm{CPA}$ & 5.4 & -2.7 & 0.7 & 6.1 & -3.0 & 0.8 \\
\hline 34-CPA & 5.5 & -2.7 & 0.7 & 5.4 & -2.7 & 0.7 \\
\hline 245T-CPA & 5.7 & -2.8 & 0.7 & 5.7 & -2.8 & 0.7 \\
\hline
\end{tabular}

\subsection{Local reactivity descriptors for neutral CPAs at the DFT level}

Additionally, consider that $\mu, \eta$, and $\omega$ are global type response functions that characterize the molecule as a whole which allow us to characterize global reactivity trends. ${ }^{23}$ But, it is important to evaluate local reactivity descriptors as $\mathrm{FF}$ to analyze the pinpoint distribution of the reactivity in the molecule. Figure 3 shows the FF isosurfaces for 4-CPA, which were obtained through the equations (8) and (9). The more nucleophilic active sites are $4 \mathrm{C}$ and $7 \mathrm{C}$ (see Figure 3a), while the most electrophilic active site is $2 \mathrm{O}$, Figure $3 \mathrm{~b}$. Similar isosurfaces to those shown in Figure 3 were obtained for 24D-CPA, 34-CPA and 245T-CPA (see Figures 1S, 2S and 3S, in supplementary material).

a)

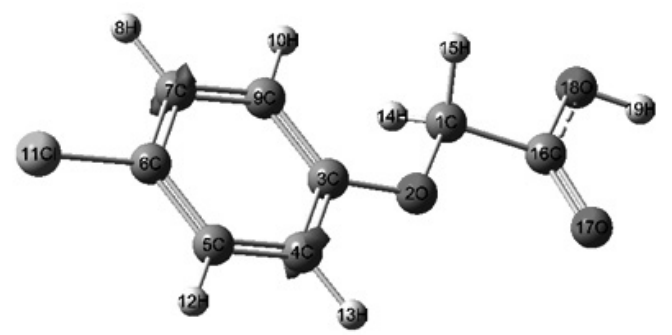

b)

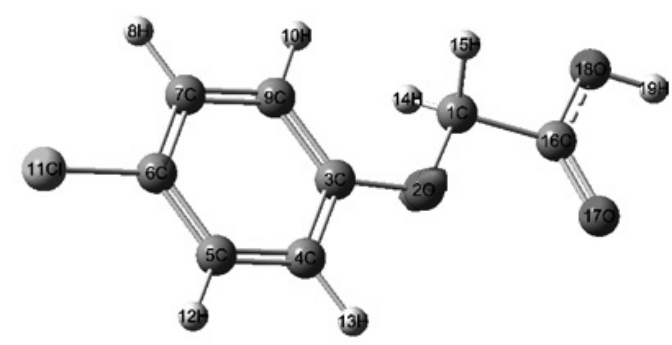

C)

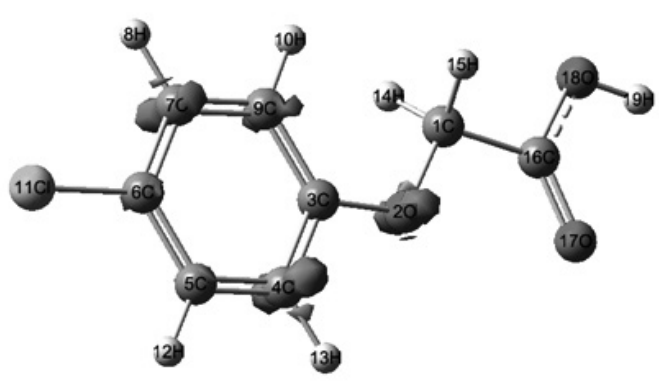

Table 2 summarizes the more reactive sites of the CPAs analyzed in the present work. Note that nucleophilic attacks on 4-CPA, 34-CPA and 245T-CPA would cause hydrogen substitutions on the aromatic ring. But, 24D-CPA a nucleophile, attacking on 4C may dechlorinate it. Also, note that in acid $\mathrm{pH}$ values, protons in solution might cause an electrophilic attack on $2 \mathrm{O}$ to produce 4-chlorophenol while electrophilic attacks on $4 \mathrm{C}$ and $7 \mathrm{C}$ atoms in 245T-CPA would cause dechlorination. The prediction of these sites is completely coincident at both MPW91B1K/6-311++G(2d,2p) and wB97XD/6$311++\mathrm{G}(2 \mathrm{~d}, 2 \mathrm{p})$ levels of theory.

Table 2. More reactive sites of 4-CPA, 24D-CPA, 34-CPA and 245T-CPA at the MPW91B1K/6-311++G(2d,2p) and wB97XD/6-311++G(2d,2p) levels of theory according to equations (8) and (9).

\begin{tabular}{|c|c|c|}
\hline Molecule & $f_{k}^{+}(\vec{r})$ & $f_{k}^{-}(\vec{r})$ \\
\hline 4 -CPA & $4 \mathrm{C}, 7 \mathrm{C}$ & $2 \mathrm{O}$ \\
\hline $24 \mathrm{D}-\mathrm{CPA}$ & $4 \mathrm{C}, 7 \mathrm{C}$ & $2 \mathrm{O}$ \\
\hline $34-\mathrm{CPA}$ & $4 \mathrm{C}, 7 \mathrm{C}$ & $2 \mathrm{O}, 6 \mathrm{C}$ \\
\hline $245 \mathrm{~T}-\mathrm{CPA}$ & $5 \mathrm{C}, 9 \mathrm{C}$ & $4 \mathrm{C}, 7 \mathrm{C}$ \\
\hline
\end{tabular}

4.2 Global and local reactivity descriptors for anionic CPAs at the DFT level.

In an aqueous environment at basic $\mathrm{pHs}$, carboxyl groups lose a $\mathrm{H}$, and they become negatively charged. Usually the carboxyl group are deprotonated at $\mathrm{pH}>7$. However, it is important to consider that the specific $\mathrm{pH}$ value, where a molecule is deprotonated depends on its $\mathrm{pKa}$ value. Thus, the pKa value reported for 4-CPA is 3.56, which indicates that at $\mathrm{pH}>3.56$ the anionic form of 4-CPA is predominant. For 24D-CPA and 245T-CPA the pKa values are 2.77 and 2.88 respectively. ${ }^{24}$ Thus, the anionic forms of 24D-CPA and 245T-CPA are predominant at $\mathrm{pH}$ values bigger than 2.77 and 2.88 respectively. On the other hand, to the best our knowledge, the pKa value for 34-CPA has not been reported in the literature. In order to identify the $\mathrm{pH}$ value where the anionic form of 34-CPA is predominant we evaluate its $\mathrm{pKa}$ value through the semiempirical method PM6 ${ }^{48}$ as implemented in MOPAC $2016,{ }^{49}$ the resulting value is 3.16 . If one calculates the pKa values for 4-CPA, 24D-CPA and 245T-CPA through this method the values are 3.27, 3.23 and 3.26 respectively, which are close to the experimental values with an average deviation of 0.39 from the experimental pka values. Thus, if one considers this average deviation, it is possible to predict that the pKa value for 34-CPA is 2.77. Under these conditions the anionic forms of 4-CPA, 24D-CPA, 34$\mathrm{CPA}$ and $245 \mathrm{~T}-\mathrm{CPA}$ are predominant at $\mathrm{pH}$ values bigger than $3.56,2.77$, 2.77 and 2.88 , respectively. ${ }^{24}$. In order to analyze the chemical reactivity of the anionic forms. They were optimized at the $\mathrm{X} / 6-311++\mathrm{G}(2 \mathrm{~d}, 2 \mathrm{p})$ level of theory (where X=MPW91B1K, wB97XD), see Figure 4. The bond distances and angle values are similar to those obtained for neutral forms, see Table 1S$4 \mathrm{~S}$ in supplementary material.

In Table 3 are reported the values of the global reactivity parameters for the anionic CPAs. Note that the $\mu, \eta$, and $\omega$ values of the anionic forms are similar to those obtained for the neutral forms. Last result indicates a similar chemical behavior of the CPAs at the different $\mathrm{pH}$ values.

Figure 3. Isosurfaces of Fukui Functions for (a) nucleophilic, and (b) electrophilic attacks on 4CPA according to equations (8) and (9). 
a)

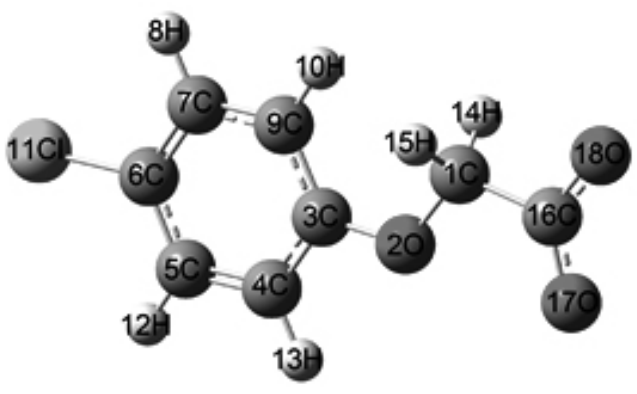

c)

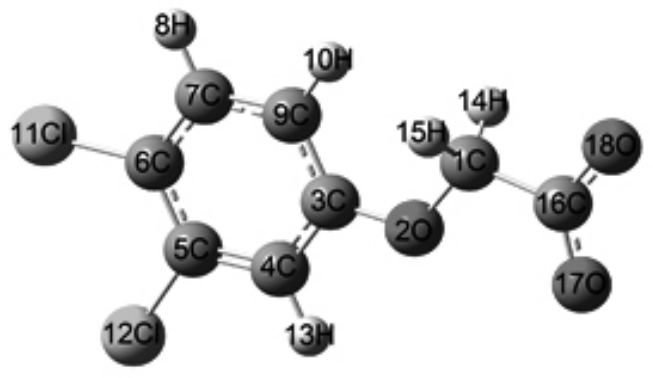

b)

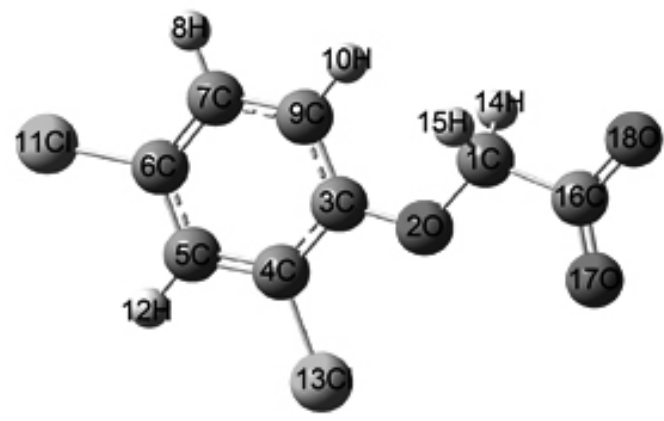

d)

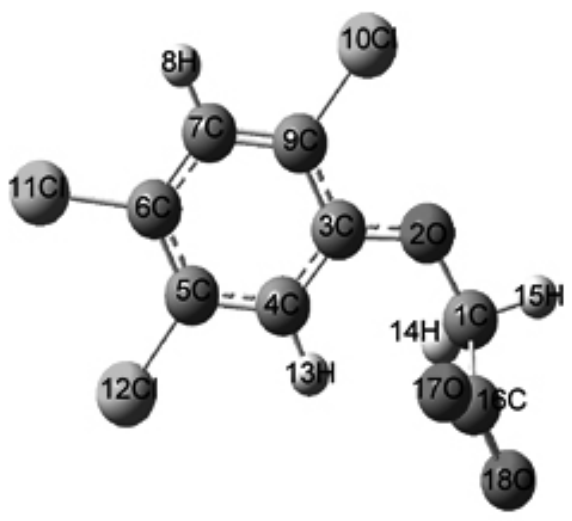

Figure 4. Optimized structures of anionic CPAs at the wB97XD/6-311++G(2d,2p) level in the aqueous phase. a) 4-CPA, b) 24D-CPA, c) 34-CPA and d)245T-CPA.

Table 3. Global reactivity descriptors for anionic CPAs: 4-CPA, 24-D-CPA, 34-CPA and 245T-CPA at the MPW91B1K/6-311++G(2d,2p) and wB97XD/6$311++\mathrm{G}(2 \mathrm{~d}, 2 \mathrm{p})$ level of theory in the aqueous phase.

\begin{tabular}{|c|c|c|c|c|c|c|}
\hline & $\eta$ & $\mu$ & $\omega$ & $\eta$ & $\mu$ & $\omega$ \\
\cline { 2 - 7 } & $/ \mathrm{eV}$ & $/ \mathrm{eV}$ & $/ \mathrm{eV}$ & $/ \mathrm{eV}$ & $/ \mathrm{eV}$ & $/ \mathrm{eV}$ \\
\hline & & MPW91B1K & & & wB97XD & \\
\hline 4-CPA & 5.8 & -2.9 & 0.7 & 5.4 & -2.7 & 0.7 \\
\hline 24D-CPA & 5.7 & -2.8 & 0.7 & 5.3 & -2.6 & 0.7 \\
\hline 34-CPA & 5.7 & -2.9 & 0.7 & 5.3 & -2.6 & 0.7 \\
\hline 245T-CPA & 5.4 & -2.7 & 0.7 & 5.1 & -2.6 & 0.6 \\
\hline
\end{tabular}

Nucleophilic and electrophilic Fukui functions for the anionic CPAs were evaluated through equations (8) and (9). Similar isosurfaces to those depicted in Figure 3 were obtained (see Figures 4S, 5S and 6S, in supplementary material) and the summary of the more reactive sites is reported in Table 4. Nucleophilic attacks in anonic 24D-CPA and 245T-CPA would cause dechlorination, while on 4-CPA and 34-CPA would cause hydrogen substitutions on the aromatic ring. The more electrophilic sites are located on $2 \mathrm{O}$ and $6 \mathrm{C}$ for 4-CPA, 24D-CPA and 245T-CPA, but 34-CPA exhibits its more electrophilic active sites on $2 \mathrm{O}$ and $4 \mathrm{C}$. These results suggest that electrophilic attacks either on $2 \mathrm{O}$ or $6 \mathrm{C}$ would cause degradation through the formation of 4-chlorophenol or dechlorination, respectively.
Table 4. More reactive sites on anionic 4-CPA, 24D-CPA, 34-CPA and 245T-CPA at the MPW91B1K/6-311++G(2d,2p) and wB97XD/6$311++G(2 d, 2 p)$ levels of theory according to equations (8) and (9).

\begin{tabular}{|c|c|c|}
\hline Molecule & $f_{k}^{+}(r)$ & $f_{k}^{-}(r)$ \\
\hline 4 -CPA & $4 \mathrm{C}, 7 \mathrm{C}$ & $2 \mathrm{O}, 6 \mathrm{C}$ \\
\hline $24 \mathrm{D}-\mathrm{CPA}$ & $4 \mathrm{C}, 7 \mathrm{C}$ & $2 \mathrm{O}, 6 \mathrm{C}$ \\
\hline $34-\mathrm{CPA}$ & $4 \mathrm{C}, 7 \mathrm{C}$ & $2 \mathrm{O}, 4 \mathrm{C}$ \\
\hline $245 \mathrm{~T}-\mathrm{CPA}$ & $4 \mathrm{C}, 7 \mathrm{C}$ & $2 \mathrm{O}, 6 \mathrm{C}$ \\
\hline
\end{tabular}

4.3 Global and local reactivity descriptors for neutral and anionic CPAs at the MP2 level.

In order to verify the chemical reactivity predictions obtained at the DFT level for the CPAs, we carried out quantum calculations at the MP2 level of 
theory. The bond distances and angle values for neutral and anionic CPAs are similar to those obtained at the DFT level, (not shown). In Table 5 are reported the values of the global reactivity parameters for neutral and anionic CPAs at the MP2/6-311++G(2d,2p) level of theory in the aqueous phase, respectively.
Note that, even though the $\boldsymbol{\mu}, \boldsymbol{\eta}$, and $w$ values are slightly larger at the MP2 level, the chemical reactivity tendency is the same to that obtained at the DFT level. Thus, the neutral and anionic forms of 4-CPA, 24-D, 34-CPA and 245T-CPA exhibit a similar global chemical behavior in aqueous conditions.

Table 5. Global reactivity descriptors for 4-CPA, 24-D, 34-CPA and 245T-CPA at the MP2/6-311++G(2d,2p) level of theory in the aqueous phase.

\begin{tabular}{|c|c|c|c|c|c|c|}
\hline & & Neutral & & & Anionic & \\
\hline & $\eta$ & $\mu$ & $\omega$ & $\eta$ & $\mu$ & $\omega$ \\
\cline { 2 - 7 } & $/ \mathrm{eV}$ & $/ \mathrm{eV}$ & $/ \mathrm{eV}$ & $/ \mathrm{eV}$ & $/ \mathrm{eV}$ & $/ \mathrm{eV}$ \\
\hline 4 4-CPA & 6.6 & -3.3 & 0.8 & 6.5 & -3.3 & 0.8 \\
\hline $24 \mathrm{D}-\mathrm{CPA}$ & 6.6 & -3.3 & 0.8 & 6.5 & -3.3 & 0.8 \\
\hline 34-CPA & 6.7 & -3.4 & 0.8 & 6.6 & -3.3 & 0.8 \\
\hline 245T-CPA & 6.6 & -3.3 & 0.8 & 6.6 & -3.3 & 0.8 \\
\hline
\end{tabular}

4.2 Local reactivity descriptors for neutral and anionic CPAs at the MP2 level

The evaluation of the nucleophilic and electrophilic FF at the MP2 level for CPAs was done through equations (8) and (9). The isosurfaces are similar to those obtained at the DFT level and the more reactive sites are summarized in the Table 6. For 24D-CPA, 34-CPA and 245T-CPA, nucleophiles would favor dechlorination while 4-CPA would be susceptible to hydrogen substitution on the aromatic ring. Electrophilic attacks to 4-CPA, 24D-CPA and 34-CPA neutral forms would cause the formation of chlorophenol while in 245T-CPA the dechlorination will be the favored process. For the deprotonated forms a nucleophilic attack on 4-CPA may cause hydrogen substitution on the aromatic ring but 24D-CPA, 34-CPA and 245T-CPA will be affected to produce dechlorinated compounds. In the case of electrophilic attacks, the formation of chlorophenol is the favored process through the cleavage of the ether bond. Here, it is interesting to highlight that a change from acid to basic $\mathrm{pH}$ values of the solution might cause that the four CPAs analyzed in the present work may be degraded employing the same method. At lower $\mathrm{pH}$ values than their corresponding pKa value, 24D-CPA, 34-CPA and 245T-CPA might be degraded by nucleophiles or electrophiles. However, 4-CPA is only affected by electrophiles at acid or basic $\mathrm{pH}$ values.

Table 6. More reactive sites on 24D-CPA, 34-CPA and 245T-CPA at the MP2/6-311++G(2d,2p) levels of theory.

\begin{tabular}{|c|c|c|c|c|}
\hline Molecule & \multicolumn{2}{|c|}{ Neutral } & \multicolumn{2}{c|}{ Anionic } \\
\hline & $f_{k}^{+}(\vec{r})$ & $f_{k}^{-}(\vec{r})$ & $f_{k}^{+}(\vec{r})$ & $f_{k}^{-}(\vec{r})$ \\
\hline 4-CPA & $5 \mathrm{C}, 7 \mathrm{C}$ & $2 \mathrm{O}, 3 \mathrm{C}$ & $4 \mathrm{C}, 7 \mathrm{C}$ & $2 \mathrm{O}, 3 \mathrm{C}$ \\
\hline 24D-CPA & $4 \mathrm{C}, 7 \mathrm{C}$ & $2 \mathrm{O}, 3 \mathrm{C}$ & $4 \mathrm{C}, 7 \mathrm{C}$ & $2 \mathrm{O}, 3 \mathrm{C}$ \\
\hline 34-CPA & $4 \mathrm{C}, 5 \mathrm{C}$ & $2 \mathrm{O}, 3 \mathrm{C}$ & $5 \mathrm{C}, 7 \mathrm{C}$ & $2 \mathrm{O}, 3 \mathrm{C}$ \\
\hline 245T-CPA & $4 \mathrm{C}, 7 \mathrm{C}$ & $13 \mathrm{Cl}, 7 \mathrm{C}$ & $4 \mathrm{C}, 7 \mathrm{C}$ & $2 \mathrm{O}, 3 \mathrm{C}$ \\
\hline
\end{tabular}

4.2 Free radical attacks on the anionic CPAS.

The evaluation of the free radical attacks for neutral forms has been reported in the literature by Ren et $\mathrm{al}^{23}$ however an analysis of this kind of reactivity on the anionic forms is missing. Following the methodology reported in previous sections, we employ the equations (8) and (9). The results indicate that, in all cases the more reactive sites for free radical attacks are located on $2 \mathrm{O}$ and $4 \mathrm{C}$, see Fig. $7 \mathrm{~S}$ in supplementary material.

\section{CONCLUSIONS}

In the present work, we have analyzed the chemical reactivity of 4-CPA, 24D-CPA, 34-CPA and 245T-CPA in their neutral and anionic forms at the DFT and MP2 levels. At both levels of theory, the results suggest that the neutral and anionic forms have a similar global reactivity. The Fukui function values suggest that electrophilic attacks would cause the formation of 4-Chlorophenol at acid and basic pHs values, while dechlorination process is caused by electrophilic attacks at basic pHs. Nucleophilic attacks would favor dechlorination and hydrogen substitutions on the aromatic ring.

\section{ACKNOWLEDGMENTS}

LHMH expresses his gratitude to the Mexican National Council for Science and Technology (CONACYT) for financing this work through the Research Project Grant 257823 and to the Universidad Autónoma del Estado de Hidalgo. Guanajuato National Laboratory (CONACyT 123732) is acknowledged for supercomputing resources. The authors like to thank SEP PRODEP for financial support through the RedNIQAE.

\section{REFERENCES}

1. T. Csrhati, E. Forgacs, J. Chromatogr. B: Biomed. Sci. Appl. 717, 157 (1998).

2. N. Serpone, E. Pelizzetti, Photocatalysis. Fundamentals and Applications, Ed. Wiley/Interscience, New York, (1989).

3. L. Türker. Turk. J. Biol. 24, 291 (2000).

4. R. L. Wain, Advan. Pest Control Res. 2, 263 (1958).

5. J. M. Charles, H. C. Cunny, R. D. Wilson, J. S. Bus, Fundam. Appl. Toxicol. 33, 161 (1996).

6. S. K. Hoar, A. Blair, F. F. Holmes, C. D. Boysen, J. R. Robel, R. Hoover, H. Fraumeni, J. Am. Med. Assoc. 256, 1141 (1986).

7. B. Hileman, Chem. Eng. News, 74, 23 (1996).

8. S. M. Bradberry, B. E. Watt, A. T. Proudfoot, J. A. Vale, J. Toxicol. Clin. Toxicol. 38, 111 (2000).

9. G. G. Bond, R. Rossbacher, Brit. J. Ind. Med. 50, 340 (1993).

10. M. Bjørling-Poulsen, H. R. Andersen, P. Grandjean, Environ. Health-UK, 7, 1 (2008).

11. J. Gao, G. Zhao, W. Shi, D. Li. Chemosphere 75, 519 (2009).

12. E. Brillas, B. Boye, I. Sires, J. A. Garrido, R. M. Rodrıguez, C. Arias, P. L. Cabot, C. Comninellis, Electrochim. Acta 49, 4487 (2004).

13. B. Boye, M.M. Dieng, E. Brillas. Environ. Sci. Technol. 36(13), 3030 (2002).

14. G. L. Sinton, L.T. Fan, L. E. Erickson, M. Lee, Enzyme Micro. Technol. 8, 395 (1986)

15. T. P. Ryan, J. A. Bumpus, Appl Microbiol Biotechnol. 31, 302 (1989).

16. J. S. Yadav, C. A. Reddy, Appl Environ Microbiol. 59, 2904 (1993).

17. E. Brillas, M. Á. Baños, M. Skoumal, P. L. Cabot, J. A. Garrido, R. M. Rodríguez. Chemosphere 68, 199 (2007).

18. L. J. Audus (Ed.), Physiology and Biochemistry of Herbicides, Academic Press, London, (1964).

19. A. S. Crafts, Chemistry and Mode of Action of Herbicides, Ed. Interscience, London, 1961.

20. A. S. Crafts and W.W. Robins, Weed Control, Ed. McGraw-Hill, London, 1962.

21. A. W. Galston, P. J. Davies, R. L. Satter, The Life of the Green Plant, Ed. Prentice-Hall, New Jersey, 1980.

22. G. S. Gruzdyev, V. A. Zinchenko, V. A. Kalinin, R. I. Slovtsov, The Chemical Protection of Plants, Ed. Mir Pub., Moscow, 1983.

23. X. Ren, Y. Sun, X. Fu, L. Zhu, Z. Cui. J. Mol. Model. 19, 2249 (2013).

24. D. Vione, M. Minella, C. Minero Phototransformation of pesticides in the Environment. In High Performance Liquid Chromatography in Pesticide Residue Analysis, edited by T. Tuzimski, J. Sherma. Editorial. CRC Press, Taylor and Francis Group. 2015

25. J. L. Gázquez, J. Mex. Chem. Soc. 52, 3 (2008). 
26. P. Geerlings, F. De Proft, W. Langenaeker, Chem. Rev. 103, 1793 (2003).

27. H. Chermette, J. Comput. Chem. 20, 129 (1999).

28. P. W. Ayers, J. S. M. Anderson, L. J. Bartolotti, Int. J. Quantum Chem. 101, 520 (2005).

29. P. K. Chattaraj, U. Sarkar, D.R. Roy, Chem. Rev. 106, 2065 (2006).

30. P. A. Johnson, L. J. P. Bartolotti, W. Ayers, T. Fievez, P. Geerlings, Modern Charge Density Analysis, ed(s) Gatti C and Macchi P Springer New York: 2012.

31. S. B. Liu, Acta Phys. Chim. Sin. 25, 590 (2009).

32. R.G. Parr, L. Szentpaly, S. Liu, J. Am. Chem. Soc. 121, 1922 (1999).

33. J. L. G. Gazquez, A. Cedillo, A. Vela, J. Phys. Chem. A 111, 1966 (2007).

34. R.G. Parr, W. Yang, Density Functional Theory of Atoms and Molecules, Oxford University Press, New York, 1989.

35. S.B. Liu, in Chemical reactivity theory: A density functional view, edited by P.K. Chattaraj, Taylor and Francis, Boca Raton, 2009.

36. J. L. Gazquez, F. Mendez, J. Phys. Chem. 98, 4591 (1994).

37. F. Mendez, J. L. Gazquez, J. Am. Chem. Soc. 116, 9298 (1994).

38. R.G. Parr, W. Yang, J. Am. Chem. Soc. 106, 4048 (1984).

39. Y. Zhao, D.G. Truhlar. J. Phys. Chem. A 108, 6908 (2004).

40. Q. Zhang, W. Yu, R. Zhang, Q. Zhou, R. Gao, W. Wang. Environ Sci Technol. 44, 3395 (2010).

41. R. Krishnan, J. S. Binkley, R. Seeger, J. A. Pople, J. Chem. Phys. 72, 650 (1980).

42. A. D. McLean, G. S. Chandler, J. Chem. Phys. 72, 5639 (1980).
43. S. Miertus, J. Tomasi, J. Chem. Phys. 65, 239 (1982).

44. S. Miertus, E. Scrocco, J. Tomasi J. Chem. Phys. 55, 117 (1981).

45. M. Head-Gordon, J.A. Pople, M. Frisch, J. Chem. Phys. Lett. 153, 503 (1988).

46. Gaussian 09, Revision A.01, M. J. Frisch, G. W. Trucks, H. B. Schlegel, G. E. Scuseria, M. A. Robb, J. R. Cheeseman, G. Scalmani, V. Barone, B. Mennucci, G. A. Petersson, H. Nakatsuji, M. Caricato, X. Li, H. P. Hratchian, A. F. Izmaylov, J. Bloino, G. Zheng, J. L. Sonnenberg, M. Hada, M. Ehara, K. Toyota, R. Fukuda, J. Hasegawa, M. Ishida, T. Nakajima, Y. Honda, O. Kitao, H. Nakai, T. Vreven, J. A. Montgomery, Jr., J. E. Peralta, F. Ogliaro, M. Bearpark, J. J. Heyd, E. Brothers, K. N. Kudin, V. N. Staroverov, R. Kobayashi, J. Normand, K. Raghavachari, A. Rendell, J. C. Burant, S. S. Iyengar, J. Tomasi, M. Cossi, N. Rega, J. M. Millam, M. Klene, J. E. Knox, J. B. Cross, V. Bakken, C. Adamo, J. Jaramillo, R. Gomperts, R. E. Stratmann, O. Yazyev, A. J. Austin, R. Cammi, C. Pomelli, J. W. Ochterski, R. L. Martin, K. Morokuma, V. G. Zakrzewski, G. A. Voth, P. Salvador, J. J. Dannenberg, S. Dapprich, A. D. Daniels, Ö. Farkas, J. B. Foresman, J. V. Ortiz, J. Cioslowski, and D. J. Fox, Gaussian, Inc., Wallingford CT, (2009).

47. Gaussview Rev. 3.09, Windows version. Gaussian Inc., Pittsburgh, (2003). 48. J.J.P. Stewart, J. Mol. Modeling 19, 1 (2013).

49. MOPAC2016, James J. P. Stewart, Stewart Computational Chemistry, Colorado Springs, CO, USA HTTP://OpenMOPAC.net (2016). 